\title{
ASPECTOS GEOAMBIENTAIS DA BACIA HIDROGRÁFICA DO CÓRREGO SANGRADOURO - CÁCERES, MATO GROSSO
}

\author{
Maxsuel Ferreira Santana ${ }^{(a)}$, Sandra Baptista da Cunha ${ }^{(b)}$, Célia Alves de Souza ${ }^{(c),}$ Verônica \\ Martinez de Oliveira Raymundi ${ }^{(a)}$ \\ (a) Mestrando em Geografia -PPGGEO/UNEMAT - maxfsantana@hotmail.com \\ (b) Professora vinculada ao PPGGEO/UNEMAT/UFF - sandracunha@openlink.com.br \\ ${ }^{(c)}$ Professora vinculada ao PPGGEO/UNEMAT - celiaalvesgeo@globo.com
}

\section{EIXO: BACIA HIDROGRÁFICA E RECURSOS HÍDRICOS: ANÁLISE PLANEJAMENTO E GESTÃO}

\section{Resumo}

Um dos caminhos para subsidiar de maneira efetiva e exitosa as problemáticas socioambientais, relacionadass às áreas úmidas, é o conhecimento dos condicionantes geoambientais. Nesse sentido o trabalho propôscompreender os aspectos geoambientais da Bacia Hidrográfica do córrego Sangradouro. Para tanto, foram desenvolvidos mapas temáticos de geomorfologia, geologia e pedologia com as bases cartográficas e informacionais do Projeto RADAMBRASIL, Folha v. 27 Corumbá e do projeto SIPAM, através do softwareSIG ArcGis versão 10.2. A amplitude altimétrica da bacia alcança até $60 \mathrm{~m}$, com grande variação da profundidade do lençol freático. Suas estruturas litológica e pedológica sãorepresentadas, principalmente, pela Formação Pantanal e pelos Latossolo Vermelho-Amarelo Distrófico, características que potencializam a frequência de alagamento da Bacia bem como o aumento de áreas úmidas. No entanto, a bacia apresenta uma baixa densidade de drenagem, com rios sem tamanhos e vazões expressivas e escoamento comprometido pelas obras de engenharia.

Palavras Chave:Áreas Úmidas, Pantanal, Condicionantes Biofísicos.

\section{INTRODUÇÃO}

O conhecimento dos aspectos geoambientais das Bacias Hidrográficas permite aferir o grau em que os componentes ambientais tornam-se condicionantes à susceptibilidade ou potencialidade aos impactossocioambientais. Nesse sentido, Gomes e Pereira (2014) também salientaram que esse conhecimento éimprescindível para os estudosde sustentabilidade, uma vez que as resposta do ambiente às ações humanas tem causado diversos problemas socioambientais.

Esse contexto ampliou os desafios suscitados às ciências na atualidadeprincipalmente quando associados às questões socioambientais, a fim de ajustar suas metodologias e/ou suas ações na busca de direcionar mecanismos e possíveis respostas que possam conduzir a soluções, que no mínimo, orientem formas adequadaspara planejar, recuperare/ou conservar as diversidades de paisagens do extrato geográfico (GUERRA e MARÇAL, 2006).

$\mathrm{Na}$ abordagem geográfico-geomorfológica, os aspectos analisados dirigem-se para uma compartimentação da paisagem, e, mais especificamente, para a identificação dos compartimentos 
OS DESAFIOS DA GEOGRAFIA FÍSICA NA FRONTEIRA DO CONHECIMENTO

Instituto de Geociências - Unicamp

Campinas - SP

28 de Junho à 02 de Julho de 2017

ambientais estruturantes da paisagem e que condicionam em maior grau os processos naturais relativos às dinâmicas do clima e da água (SCHUTZER, 2012).

Jiménez-Ruedaet al. (1998), dizem que o conhecimento e definição dos grandes domínios morfoestruturais, da morfologia do relevo, dos condicionantes climáticos e bióticos, são fundamentais para compreensão e determinação dos fatores da dinâmica evolutiva de uma paisagem.

A análise morfoestruturalaplicada a questões ambientais em muito pode contribuir para o conhecimento sobre o meio físico, pois, permite compreender aspectos relacionados à dinâmica das paisagens e, assim, planejar o uso dos recursos naturais de acordo com suas potencialidades e fragilidades (MOURA e JIMÉNEZ-RUEDA, 2014).

Estudos referentes ao conhecimento da morfologia do ambiente físico foram desenvolvidos por Santos (2010) no Paraná; Gomig (2012) no médio Araguaia; e no Pantanal Matogrossense por Pereiraet al. (2012).

Diante disso é notório que, para o conhecimento mais amplo das questões ambientais necessita-se de estudos mais detalhados a níveis de Bacias hidrográficas. Nesse sentido, o trabalho se propôs em compreender os aspectos geoambientais da Bacia Hidrográfica do córrego Sangradouro.

\section{MATERIAL E MÉTODO}

\subsection{Localização da Área de Estudo}

A Bacia do Córrego Sangradouro está localizada a margem esquerda do Rio Paraguai e se constitui como parte das cabeceiras do Pantanal, umas das maiores e mais importantes zonas úmidas do planeta. Localizada entre as coordenadas $16^{\circ} 02^{\prime} 00^{\prime \prime}$ e $16^{\circ} 08^{\prime \prime} 00^{\prime \prime}$ de latitude Sul; e $57^{\circ} 42^{\prime} 00^{\prime \prime}$ e 57³6’00” de longitude Oeste, situa-se no Município de Cáceres - Sudoeste do Estado de Mato Grosso e abrange grande área do perímetro urbano da cidade de Cáceres. No entanto, sua extensa área de nascente se estendeentre as Serra do Lobo e as da Serra Bom Jardim delineando a Depressão do Alto Paraguai até a sua foz na Baia do Malheiros,no rio Paraguai (Figura 1).

A definição do canal principal da bacia foi definida pela toponímia local, conforme a denominação dada pela população. Esse canal foi nominado de Sangradouro, no entanto, este é o menor canal em extensão, ao passo que o Lava-Pés apresenta a maior extensão. Nesse sentido, no presente trabalho a bacia será denominada de Bacia do Córrego Sangradouro.

Em sequencia, essa bacia será contextualizada quanto às características da estrutura física da geomorfologia regional, esse entendimento permitirá compreender o contexto de como se estruturou o embasamento onde a Bacia do Sangradouro se estabeleceu e os condicionantes que determinou as 
características do relevo atual onde o município de Cáceres foi estabelecido. Esse conhecimento permitiu compreender, também, a área fonte, primária, da cobertura sedimentar presente da Bacia.

Figura 1 - Localização da Bacia do Córrego Sangradouro. 


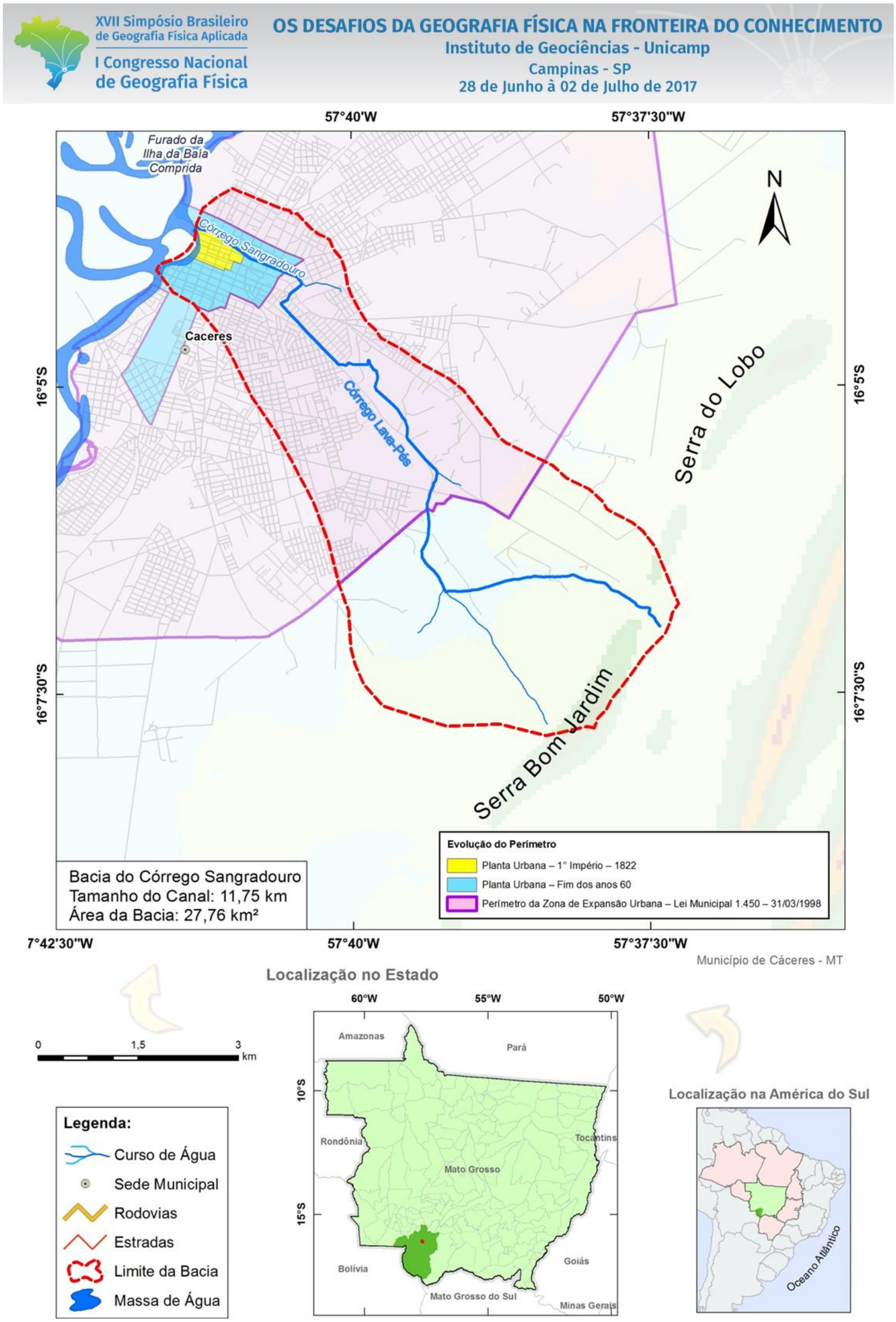

Fonte: Adaptado dos Dados Cartográficos do IBGE.Org.: Gilmar de S. Acácio.

\subsection{Procedimentos Metodológicos}


Para o conhecimento das características dos aspectos geoambientais da bacia do Sangradouro, foram confeccionados mapas temáticos de geologia, geomorfologia e pedologia com base cartográfica obtidas do Relatório de Recursos Naturais do Projeto - RADAMBRASIL, Folha v. 27 Corumbá. A projeção utilizada foi a Universal Transversa MercatorMerdiano Central - 57 $\mathrm{W}$.Gr. Situação Física janeiro de 2017, desenvolvido através do software SIG ArcGis, versão 10.2.

Para o levantamento da caracterização das unidades geomorfológicas e geológicas,foram utilizados as informações do Relatório de Recursos Naturais do ProjetoBRASIL, Folha v. 27 Corumbáe Folha SD.21-Cuiabá. As demais informações pertinentes ao estudo foramobtidas a partir de livros, teses, dissertações, artigos científicos e observações de campo, que auxiliou no reconhecimento das característicasfisionômicas do ambiente.

\section{RESULTADOS E DISCUSSÃO}

\subsection{ASPECTOS GEOMORFOLÓGICOS}

A Bacia do córrego Sangradouro está inserida em um contexto estrutural representados por três grandes unidades geomorfológicas, são elas: Província Serrana, Depressão do Rio Paraguai epelos Pantanais Mato-grossenses. A setorização da bacia (em alto, médio e baixo curso) não é bem definida, por conta da baixa amplitude topográfica em aproximadamente $80 \%$ da sua área com amplitude de 19 $\mathrm{m}$, no entanto, considerando os pontos mais elevados da depressão a amplitude chega a $60 \mathrm{~m}$.

Suas nascentes foram estabelecidas entre a Serra do Lobo e a Serra do Bom Jardim na Província Serrana. As características da área como, a capacidade de infiltração do solo, a proximidade do lençol freático à superfície, litologia e a topografia a, condicionaram do tipo difusa,ou seja, não se concentra em único ponto, mas se distribui numa vasta área úmida na depressão. Os canais se convergem até a desembocadura na Baía do Malheiros no Rio Paraguai,abarcando grande área do perímetro urbano da cidade de Cáceres - MT.

Os relevos de topografia mais elevada é a Província Serrana, representada pela Serra do Lobo com altitude de até319 me pela Serra Bom Jardim com altitude que alcança $314 \mathrm{~m}$. O conjunto Serrano é do tipo Apalachiano que, segundo Brasil (1982 b) é o primeiro desse tipo a ser identificado no território brasileiro. Brasil (1982 b)ainda destaca que de forma geral, o Conjunto Serrano é esculpido em estrutura dobrada de idade antiga. Apresenta sucessões de sinclinais e anticlinais de estrutura simples; sinclinais alçadas, anticlinais escavadas e relevos invertidos; cristas paralelas entre si, comportando truncamento de topo e moldadas em rochas duras (Formação Raizama), com vales abertos em rochas tenras ou friáveis (Formação Sepotuba eFormação Diamantino). 
Para Ross (1991), a formação do conjunto Serrano foi resultado dos processos orogênicos do Pré-cambriano Superior associado ao contexto geotectônico de formação dos cinturões orogenéticos do Ciclo Brasiliano. Esse processo resultou no Geossinclíneo Paraguai-Araguaia, desenvolvendo-se a partir de duas bacias geossinclinais (litológicas) denominadas de Grupo Cuiabá (eugeossinclinal) e Grupo do Alto Paraguai (miogeossiclinal). Essa última é a mais recente e atualmente é representada pelo conjunto Serrano.

De forma geral, a forma da bacia é resultado de processos de aplainamento regional e recobertos por sedimentos recentes, a topografia da bacia apresenta uma baixa amplitude altimétrica e caracteriza-se como um relevo predominantemente plano e suave ondulado. A drenagem é composta por diversos canais pequenos, os mais importantes são representados pelos córregos Lava Pés e o Sangradouro de direção SE-NW. A depressão é marcada pela drenagem e por uma extensa área úmida que compões a bacia, no entantoos canais fluviais que formam a drenagem não são expressivos em tamanho e no volume de água. Oseu escoamento foi comprometidopelas obras de engenharia, como a construção de pontes, alargamento e aprofundamento do canal, que afeta de forma negativa o fluxo de água, interferindo na dinâmica fluvial dos canais.

Na Depressão, o segmento que se estende da nascente até a sua foz,é caracterizado por variados tipos de ocupação, como fazendas, chácaras e, áreas residenciais e comerciais. Essa depressão corresponde a uma superfície de relevo pouco dissecado com pequeno caimento topográfico de norte para sule de Leste a Oeste, com altimetria reduzida, inferior a200m. Brasil (1982 a) ao descrevê-la de forma mais abrangente, descreve que a mesma seconstituiem cinturões marginais aos relevos elevados caracterizadas por extensas superfícies aplanadas com suaves ondulações, que por vezes apresentam superfícies pediplanadas e/ou inumadas, recobertas por sedimentos recentes. Acompanhando vales sinclinais e/ouse sobrepondo as anticlinais escavadas com altitudes reduzidas, variando de 120 e 300.

O baixo curso da Bacia tem sua formação vinculada a acumulações fluviais associadas à Formação Pantanal, esse contexto mostra que a Depressão do Rio Paraguai coalesce com o Pantanal de Cáceres. Essa por sua vez é periodicamente alagada, tendo as enchentes como inerente à sua característica. Ross (2016) descreve que a formação da planície e da depressão possui uma relação com a orogênese Andina, ou seja, a gênese dessa unidade geomorfológica estaria vinculada aos abatimentos tectônicos desses processos, o que promoveu uma área rebaixada onde se alojaram os pantanais. Em relação à cobertura do Pantanal do Rio Paraguai, sua origem é fluvial datadas do Quaternário (Pleistoceno e Holoceno). Ross (2016, p. 44) a descreve da seguinte maneira.

Esse Pantanal, cujas altitudes estão entre 100 e 150 m, compõe-se de um pacote sedimentar terciário-quaternário, cujas espessuras maiores atingem pouco mais de $400 \mathrm{~m}$. Os sedimentos inconsolidados de superfície, que sustentam os relevos baixos, são decorrentes de processos deposicionais em sistemas de leques 


\section{OS DESAFIOS DA GEOGRAFIA FÍSICA NA FRONTEIRA DO CONHECIMENTO \\ Instituto de Geociências - Unicamp \\ Campinas - SP \\ 28 de Junho à 02 de Julho de 2017}

aluviais que, ao longo do Pleistoceno e Holoceno, ao mesmo tempo se acumulavam, nos transbordamentos fluviais das inundações, se desgastavam e se remanejavam.

Nos estudos de Santana e Souza (2015) e Souza (2004), os autores evidenciam que a morfologia do corredor fluvial do Rio Paraguai é controlada pelos processos hidrossedimentológicos e também pelo comportamento hidroclimático. Souza (2004) ainda destaca queos condicionantes geomorfológicos e hidrológicos permitem a manutenção da biodiversidade do corredor fluvial através do aporte de água, sedimentos e nutrientes, bem como, aos aspectos que caracterizam a paisagem regional.

Figura 2: Geomorfologia da Bacia.

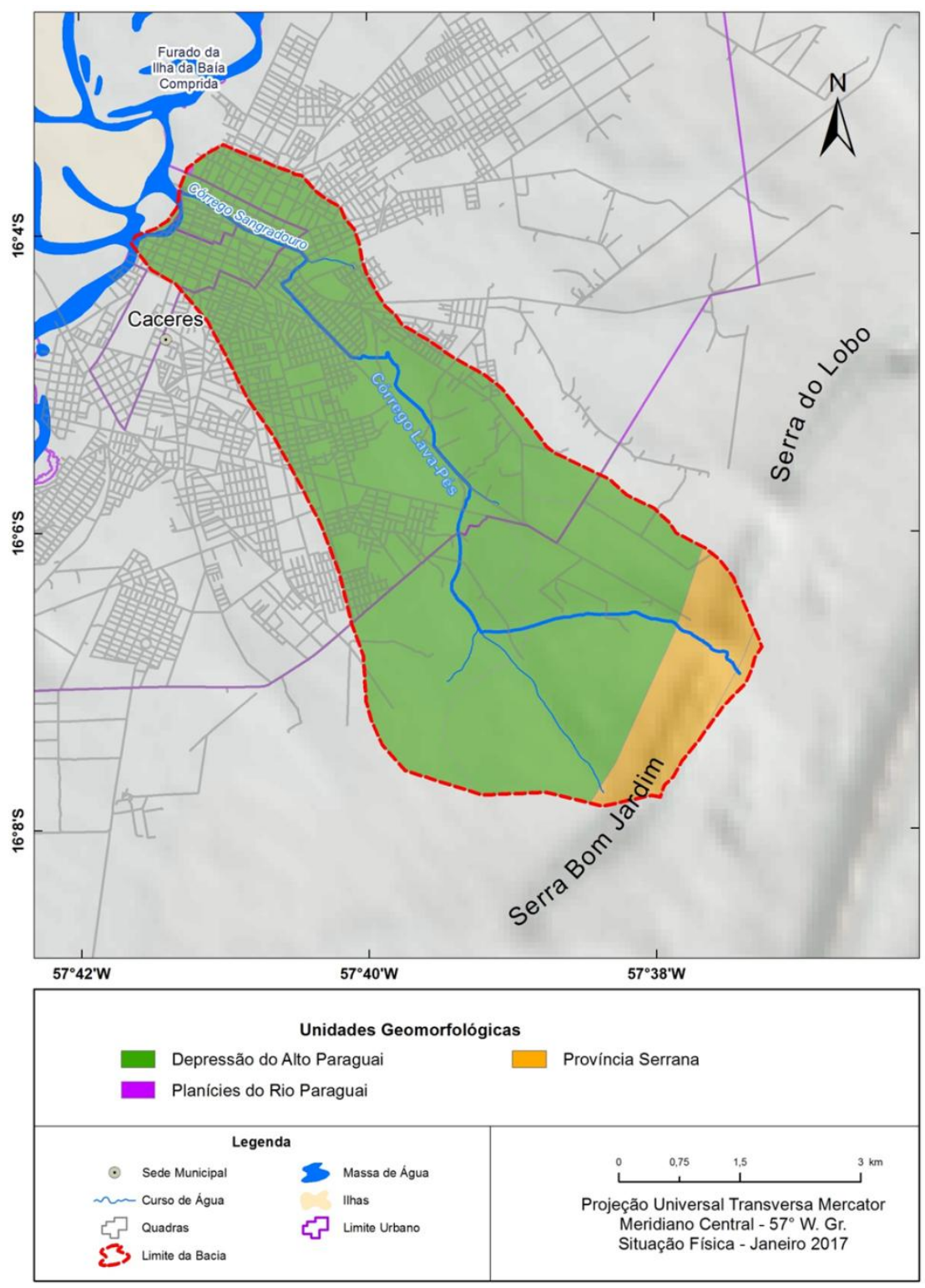

Fonte: Adaptado dos Dados Cartográficos do IBGE. Org.: Gilmar de S. Acácio.

\subsection{ASPECTOS LITOLÓGICOS}


OS DESAFIOS DA GEOGRAFIA FÍSICA NA FRONTEIRA DO CONHECIMENTO Instituto de Geociências - Unicamp

Campinas - SP

28 de Junho à 02 de Julho de 2017

A Bacia do córrego Sangradouro é constituída pelas seguintes formações litológicas: Formação Raizama e Araras no alto curso, em praticamente toda a Bacia a o predomínio dasCoberturas Detrito-Laterítica, e na área de foz depósitos quaternárias associadas às acumulações fluviais.

Os relevos de topografia com maior elevação, no alto curso da Bacia, são representados pelas Serra do Lobo e Serra Bom Jardim esuas litologias são representadas pelos arenitos quartzosas efeldspáticospertencentes àFormação Raizama. Brasil (1982b) descreve que nessa formação a presença de arenitos em cores variegados de granulação fina a média com frequentes níveis de areia grossa, seixos e grânulos. Os feldspatos quase sempre estão alterados e são mais abundantes por arenitos de granulação fina, sendo comuns as intercalações de siltítos e argilitos.

Nos vales entre as serras a litologia é composta por calcários calcíticos e dolomíticos pertencentes à Formação Araras. O afloramento calcário é devido à intensa erosão nas antigas camadassuperiores, essas camadas eram pertencentes à formação Raizama e Sepotuba (folhelhos e siltítos). De forma mais ampla, Brasil (1982b) explicita que a presença de calcário calcíticos com intercalações de margas e siltítos, gradam para calcários com intercalações de siltítos e dolomitos no topo, com a presença de contatos transicionais da base para o topo.

A litologia predominante na Bacia, principalmente no médio curso, é constituída por depósitos Detríticospertencentes ao quaternário, à obra supracitada ainda descreve que esse material éconstituído por colúvios e materiais aluviais com a presença de blocos arredondados de arenitos da formação Raizama cimentados por hidróxidos férricos, materiais que inumaram as rochas do Grupo Alto Paraguai. Encontram-se, também, blocos e matacões soltos, evidenciando processos erosivos recentes e atuantes.

Rosestolato-Filho (2006) descreve que, geologicamente, a cidade de Cáceres está situada sobre a Formação Pantanal, caracterizada por sedimentos aluviais dominantemente arenosos,sílticoargilosos e argilosos, inconsolidados esemiconsolidados. O autor ainda destacou a presença da Formação Diamantina (metapelito) o que condiciona a grande variação donível do lençol freático no perímetro urbano.

A deposição e as características texturais dessas formações fazem supor que a área passou por diversas variações climáticas e por diversos processos erosivos, nesse sentido Brasil (1982b) descreve os fatores supracitados podem ter condicionado a formação de grandes leques aluviais que compõem o nível superior da Formação Pantanal. Esse contexto pode explicar um dos fatoresque condicionarama bacia como uma área susceptível ao alagamento periódico.

Figura 3: Geologia da Bacia. 


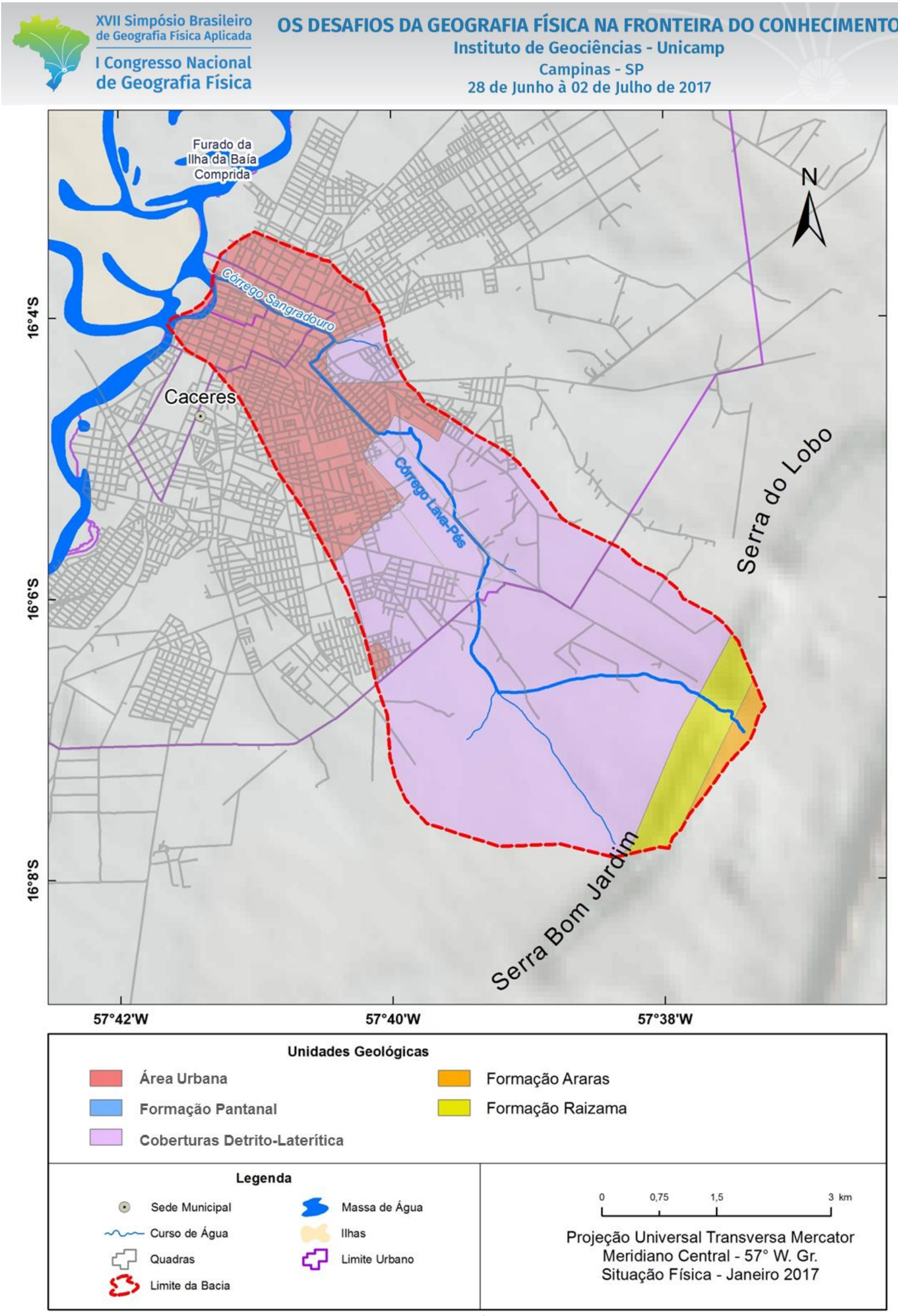

Fonte: Adaptado dos Dados Cartográficos do IBGE. Org.: Gilmar de S. Acácio.

\subsection{ASPECTOS PEDOLÓGICOS}


XVII Simpósio Brasileiro

de Geografia Fisica Aplicada

I Congresso Nacional

de Geografia Física
OS DESAFIOS DA GEOGRAFIA FÍSICA NA FRONTEIRA DO CONHECIMENTO

Instituto de Geociências - Unicamp

Campinas - SP

28 de Junho à 02 de Julho de 2017

Os tipos de solos presentes no alto curso da bacia, nas serras, são formados por NeossoloLitólico Distrófico (Solos Litólicos)sobreposto à formação Raizama nas altimetrias de até $319 \mathrm{~m}$. Esse solo apresenta baixa fertilidade e formado por material mineral, ou orgânicocom menos de $20 \mathrm{~cm}$ de espessura, não apresentando qualquer tipo de horizonte Bdiagnóstico.

O IBGE (2007) descreve que de forma de geral esse solo possui pavimento pedregoso que não pode ser facilmente removido, constituídos por material mineral ou material orgânico pouco espesso (menos de $30 \mathrm{~cm}$ de espessura), com saturação por bases baixa $(\mathrm{V}<50 \%)$. O Neossolo Litólico é encontrado, praticamente, em todas as regiões do País embora sem constituir representatividade espacial expressiva nos relevos muito acidentados de morrarias e serras.

O Argilossolo Vermelho-Amarelo Eutrófico pode ser encontrado sobreposto aos folhelhos e siltítos da Formação Sepotuba nos vales da Província Serrana no alto curso da Bacia. Conforme Embrapa (2006), esse tipo de solo possui saturação por bases ${ }^{3} 50 \%$ na maior parte dos primeiros 100 cm do horizonte B (inclusive BA). IBGE (2007) diz que sua profundidade é variável, mas em geral são pouco profundos e profundos, sendo marcante um aumento de argila do horizonte superficial A para o subsuperficial B que é do tipo textural (Bt), geralmente acompanhado de boa diferenciação também de cores e outras características. São juntamente com os Latossolos, os solos mais expressivos do Brasil, sendo verificados em praticamente todas as regiões.

O solo predominante na bacia é o Latossolo Vermelho-Amarelo Distrófico, o mesmo abrange praticamente toda a superfície da Depressão, caracteriza por apresentar diferentes profundidas, excessivamente drenado e bastante permeável, logo sua capacidade de fertilidade é baixa. Brasil (1982b) o descreve com A moderado e textura argilosacom pequena relação textual e pouca diferenciação entre os horizontes. A formação litológica é representada pelos depósitos DetritoLateríticos com litologias constituídas por argilas e concreções limoníticas produtos de alteração de rochas subjacentes, com drenagem acentuada.

No entanto, Rosestolato-Filho (2006) destacou em seu estudo realizado na cidade de Cáceres a presença de solos arenosos pertencentes à Formação Pantanal, e a presença de camadas argilosas pertenceà Formação Diamantino o que condicionariauma grande variação do nível do lençol freático no perimetro urbano, formando Plintossolos, minerais de argila e várias áreas de embaciamento.

No baixo curso, área de formação antiga pela acumulação fluvial, apresentaGleissoloHáplicotbEutrófico, solo comum em áreas alagadas ou sujeitas a alagamentos (margens de rios, ilhas, grandes planícies, etc.). Dessa maneira, esses dois tipos de solo ocorrem em praticamente todas as regiões brasileiras, ocupando principalmente as planícies de inundação de rios e córregos. Apresentam cores acinzentadas, azuladas ou esverdeadas, dentro de $50 \mathrm{~cm}$ do perfil, sendo frequente a ocorrência de mosqueado. Podem ser de alta ou baixa fertilidade natural e têm nas condições de má drenagem a sua maior limitação de uso (IBGE, 2007).

Figura 3: Pedologia da Bacia. 


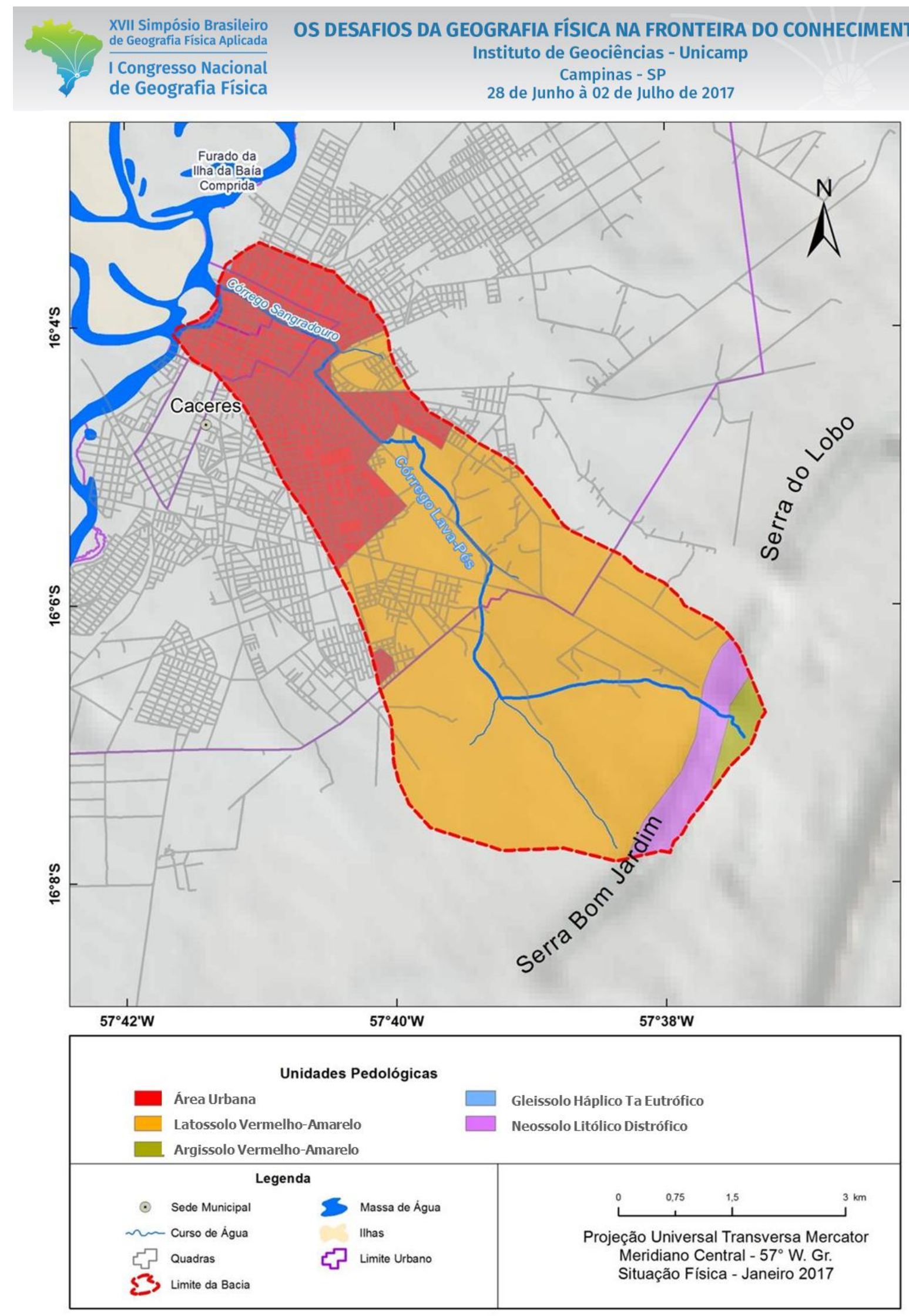

Fonte: Adaptado dos Dados Cartográficos do IBGE. Org.: Gilmar de S. Acácio.

\section{Considerações Finais}


OS DESAFIOS DA GEOGRAFIA FÍSICA NA FRONTEIRA DO CONHECIMENTO

Instituto de Geociências - Unicamp

Campinas - SP

28 de Junho à 02 de Julho de 2017

A área que compreende a Bacia do córrego Sangradouro se estende por uma grande área da Depressão do Rio Paraguai, essa recoberta por Depósitos Detríticos quaternário e pelo predominante Latossolo Vermelho-Amarelo Distrófico. Sua gênese está vinculada aosprocessos de formação das unidades ambientais que estruturam a bacia, representadas pela Província Serrana, Depressão do Rio Paraguai e pelos Pantanais Matogrossense.

A baixa amplitude altimétrica, a grande variação do lençol freático e, sua estrutura litológica e pedológica, representados, principalmente, pela Formação Pantanal e pelos Latossolo VermelhoAmarelo Distrófico, potencializam a capacidade de alagamento da Bacia bem como o aumento de áreas úmidas. No entanto, a bacia apresenta uma baixa densidade de drenagem, com rios sem tamanhos e vazões expressivas, com o escoamento comprometido pelas obras de engenharia.

Os conhecimentos dos aspectos geoambientais permitem auxiliar no planejamento do desenvolvimento urbano, pois é possível através de estudos dessa natureza, o conhecimento da susceptibilidade e potencialidade do ambiente aos tipos uso do solo e/ou para a sua conservação.

\section{Agradecimentos:}

Ao apoio do Programa de Pós-graduação em Geografia - PPGGEO, ao Laboratório de Estudos e Pesquisa em Geomorfologia Fluvial "Prof ${ }^{a}$ Sandra Baptista da Cunha" - LAPEGEOF e a CAPES, pelo apoio financeiro.

\section{REFERÊNCIAS}

BRASIL. Ministério das Minas e Energia. Secretaria-Geral. Projeto RADAMBRASIL v. 27 Corumbá; geologia, geomorfologia, pedologia, vegetação e uso potencial da terra. Rio de Janeiro, 1982 a.

BRASIL. Ministério das Minas e Energia. Secretaria-Geral. Projeto RADAMBRASIL. Folha SD-21 Cuiabá; geologia, geomorfologia, pedologia, vegetação e uso potencial da terra. Rio de Janeiro, 1982 b.

CASSETI, Valter. Geomorfologia. [S.1.], 2005. Disponível em: <http://www.funape.org.br/geomorfologia/>. Acesso em: 15 de jan. 2017.

EMBRAPA - Serviço Nacional de Levantamento e Conservação de Solos. Sistema brasileiro de classificação de solos. 2. ed. - Rio de Janeiro : EMBRAPA-SPI, 2006, 306 p..

GOMES, M.F.A.; PEREIRA, L. C.. Aspectos Geoambientais e Áreas Frágeis no Brasil. Revista Intellectus. $\mathrm{N}^{\circ}$ 26 Vol. 01, Ano X [26] - Janeiro/Março, 2014, p. 5-19.

GOMIG, E. G.. Estudo do meio físíco para o uso da terra na Bacia do Rio Sete de Setembro - médio Araguaia. Dissertação (Mestrado em Geociências e Meio Ambiente). Rio Claro : [s.n.], 2012.

GUERRA, A. J. T. e MARÇAL, M. dos S.. Geomorfologia Ambiental. Rio de janeiro: Bertrand Brasil, 2006.

IBGE - Instituto Brasileiro de Geografia e Estatística. Ministério de Planejamento, Orçamento e Gestão.

Manual Técnico de Pedologia. $2^{\mathrm{a}}$ ed., Rio de Janeiro, 2007.

IBGE - Instituto Brasileiro de Geografia e Estatística. Ministério de Planejamento, Orçamento e Gestão. Mapa Geomorfológico. $1^{\text {a }}$ ed., Rio de Janeiro, 2009. Disponível em:

<ftp://geoftp.ibge.gov.br/informacoes_ambientais/geomorfologia/mapas/unidades_da_federacao/mt_geomorfolo gia.pdf>. Acesso em: 15 de jan. 2017. 
JIMÉNEZ-RUEDA, J. R.; PESSOTTI, J. E. S. e MATTOS, J. T.. Modelo para o estudo da dinâmica evolutiva dos aspectos fisiográficos dos pantanais. Pesq. agropec. bras., Brasília, v.33, Número Especial, p.1763-1773, out. 1998

MOURA, C. A. e JIMÉNEZ-RUEDA, J. R.. Aplicação da análise morfoestrutural na caracterização da aptidão do meio físico a múltiplos usos em Caraguatatuba - SP. Revista de Geografia (UFPE) V. 31, No. 1, 2014.

PEREIRA, G.; CHÁVEZ, E. S.; SILVA, M. E. S. O estudo das unidades de paisagem do bioma Pantanal. Ambiente \& Água, Taubaté, v. 7, n. 1, p. 89-103, 2012.

ROSESTOLATO-FILHO, A. Geomorfologia aplicada ao saneamento básico na cidade de Cáceres, Mato grosso. Tese (Doutorado em Geografia), Rio de Janeiro: Universidade Federal do Rio de Janeiro, 2006, 144 f..

ROSS, J. L. S.. O Relevo Brasileiro no contexto da América do Sul. R. Bras. Geogr., Rio de Janeiro, v. 61, n. 1, p. 21-58, jan./jun. 2016.

ROSS, J. S.. O Contexto Geotectônico e a Morfogênese da Província Serrana de Mato Grosso. Rev. IG, São Paulo, 12 (1/2), 21-37, jan./dez./ 1991.

SANTANA, M. F.; SOUZA, C. A.. Compartimentos Geomorfológicos e sua influencia na orfologia Fluvial do rio Paraguai no segmento entre a Volta do Angical à Foz do rio Sepotuba. Enciclopédia Biosfera, Centro Científico Conhecer - Goiânia, v.11 n.21; p. 2015.

SANTOS, F. R. Condicionamento morfoestrutural do relevo e neotectônica da bacia Hidrográfica do Bufadeira - Faxinal/ PR. Dissertação (Mestrado em Geografia). Maringá : Universidade Estadual de Maringá, 2010).

SCHUTZER, J. G.. Dispersão Urbana e Apropriação do Relevo na Macrometrópole de São Paulo. Tese (Doutorado em Geografia). São Paulo: Universidade de São Paulo, 2012.

SOUZA, C. A. Ambiente do Corredor Fluvial do rio Paraguai entre a cidade de Cáceres e a Estação Ecológica da Ilha de Taiamã - MT. Tese (Doutorado em Geografia) - Universidade Federal do Rio de Janeiro, Rio de Janeiro, 2004. 